\title{
A LETRA E A ESCRITA A NÃO SE LEREM
}

THE LETTER AND THE WRITING ARE NOT TO BE READ

\section{LA LETRA Y LA ESCRITURA NO LEEN}

Ricardo Monteiro Guedes de Almeida*

\begin{abstract}
RESUMO
O conceito de letra convoca uma discussão sobre a prática da interpretação psicanalítica. Assim, objetivamos realizar um percurso sobre a letra e a hipótese lacaniana de que o escrito não é para ser lido. Recorremos a um estudo teórico no qual, primeiramente, versamos sobre o significante e a letra, tal como Lacan propôs no texto $A$ instância da letra no inconsciente ou a razão desde Freud. Posteriormente, aprofundamos na distinção entre esses dois conceitos, visando ao Seminário, Livro 18. Por fim, discutimos a afirmação de Lacan sobre a impossibilidade da leitura do escrito. Considerando o papel que a letra e a função do escrito assumem no campo do gozo e no alcance de uma análise, concluímos que a letra não é só distinta do significante como também corresponde a uma escrita que está no real, representando, assim, a incidência de um limite do sentido e da própria interpretação.
\end{abstract}

Palavras-chave: Significante. Letra. Função do escrito. Gozo.

\begin{abstract}
The concept of a letter calls for a discussion about the practice of psychoanalytic interpretation. Thus, we aim to make a course about the letter and the Lacanian hypothesis that the writing is not meant to be read. We turn to a theoretical study where, at first, we deal with the signifier and the letter, as Lacan proposed in the text The instance of the letter in the unconscious, or the reason since Freud. Later, we delved into the distinction between these two concepts, aiming at the Seminar, Book 18. Finally, we discuss Lacan's statement about the impossibility of reading the writing. Considering the role that the letter and the function of the writing assume in the field of jouissance and in the scope of an analysis, we conclude the letter is not only distinct from the signifier but also corresponds to a writing that is in the real, thus representing the incidence limit of meaning and interpretation itself.
\end{abstract}

Keywords: Significant. Letter. Function of writing. Jouissance.

\footnotetext{
Texto recebido em 3 de maio de 2017 e aprovado para publicação em 20 de março de 2018.

"Doutorando e mestre em Psicologia Social pela Pontifícia Universidade Católica de São Paulo (PUC-SP), membro do Núcleo de Pesquisa "Psicanálise e Sociedade" nessa instituição, psicólogo e psicanalista. Endereço: Avenida Francisco Matarazzo, 43, ap. 95 - Água Branca, São Paulo-SP, Brasil. CEP: 05001-000. Telefone: (83) 98839-8039. E-mail: ricardopsi@gmail.com
} 


\section{RESUMEN}

El concepto de letra convoca a una discusión sobre la práctica de la interpretación psicoanalítica. Por lo tanto, nuestro objetivo era realizar un recorrido sobre la letra y la hipótesis lacaniana de que lo escrito no es para ser leído. Realizamos un estudio teórico en el que, en primer lugar, hablamos sobre el significante y la letra, como se propone en el texto de Lacan, La instancia de la letra en el inconsciente o la razón desde Freud. Más tarde, profundizamos en la distinción de estos dos conceptos, mirando al Seminario, Libro 18. Por último, se discute la afirmación de Lacan sobre la imposibilidad de lectura de lo escrito. Teniendo en cuenta la importancia de la letra y la función de la escritura en el campo del goce y en el alcance de un análisis, llegamos a la conclusión de que la letra no sólo es distinta del significante sino también corresponde a una escritura que se encuentra en lo real, lo que representa la incidencia un límite del sentido y de la propia interpretación.

Palabras-clave: Significante. Letra. Función de la escritura. Goce.

\section{INTRODUÇÃO}

P

ara abordarmos a letra e a escrita "a não se ler", uma introdução ao significante e ao campo da linguística se faz necessária. Considerando o aforismo lacaniano de que o inconsciente é estruturado como linguagem e aceitando o conselho de Lacan (1957/1998), ${ }^{1}$ de que o analista deve introduzirse na distinção fundamental entre o significante e o significado, assim como exercitar-se nas duas redes de relações que lhes pertencem, iniciamos este trabalho abordando alguns dos elementos da teoria saussuriana.

Saussure (1970), em sua reflexão quanto ao algoritmo estrutural da linguagem, adotou uma posição extremamente crítica ante os velhos pontos de vista, que relacionam a língua ao simples sentido de nomenclatura, em que se cria um vínculo entre o nome e uma coisa, uma associação que, de forma alguma, permite verificar se "a palavra é de natureza vocal ou psíquica" (Saussure, 1970, p. 79).

O signo linguístico saussuriano não é visto como uma associação de um nome a uma coisa, mas como um conceito que relaciona a uma imagem acústica, sendo que esta última "não é o som material, coisa puramente física, mais a impressão (empreinte) psíquica desse som, a representação que dele nos dá o testemunho de nossos sentidos" (Saussure, 1970, p. 80, grifo do autor).

\footnotetext{
${ }^{1}$ A primeira data indica o ano de publicação da obra, e a segunda, a edição consultada pelo autor, a qual somente será pontuada na primeira citação da obra no texto. Nas seguintes, será registrada apenas a data de publicação original.
} 
Partindo do princípio de que o signo é uma associação entre conceito e imagem acústica, poderíamos chegar à conclusão, a exemplo de Saussure (1970), de que esse signo é uma entidade psíquica com duas faces, que estão intimamente unidas, ao ponto de uma reclamar à outra. Porém, é importante ressaltar que Lacan (1957) rompeu com essa visão, adotando uma perspectiva mais autonômica entre ambas. Assim, enquanto Saussure (1970) tratou de uma dualidade entre essas faces, ao ponto de utilizar uma folha de papel como analogia e usá-la para determinar que "não se pode cortar o anverso sem cortar ao mesmo tempo o reverso" (Saussure, 1970, p. 131), Lacan (1955-1956/2008) apontou uma duplicidade entre as duas faces, como é possível observar em uma passagem do Seminário 3: as psicoses: "Sem a duplicidade fundamental do significante e do significado, não há determinismo psicanalítico concebível” (p. 136).

Essa duplicidade indicada por Lacan (1955-1956) não se configura em uma relação plenamente fixa, tal como foi proposta por Saussure. $\mathrm{O}$ algoritmo como Lacan (1955-1956) o concebeu diferencia-se do signo saussuriano não somente pela inversão da localização do significante e do significado. O significante, no signo lacaniano, localiza-se no topo, sendo representado por uma letra maiúscula. Já o significado é posto abaixo e tem sua representação por letra minúscula e itálica $(\mathrm{S} / s)$. Mas, além disso, esse algoritmo também se distingue por conta da ênfase que Lacan associou à barra entre os dois. Na verdade, Saussure, com a perspectiva de que o significado e o significante estão intimamente unidos, nunca destacou o traço como uma "barra" que, por si só, apresenta um sentido de resistência e separação (Arrivé, 2001).

$\mathrm{Na}$ associação do significante e do significado, "O laço que une o significante com o significado é arbitrário” (Saussure, 1970, p. 81), o que significa dizer que um conceito não é representado por uma única montagem acústica, como se pode observar quando diferentes linguagens representam um mesmo conceito, um mesmo significado. Todavia, o arbitrário do signo não se remete a uma aleatoriedade, já que ele apenas diz respeito a um conjunto de uma determinada comunidade linguística, como Saussure (1970, p. 83) apresenta: "A palavra arbitrário requer também uma observação. Não deve dar a ideia de que o significado depende da livre escolha do que fala". O que significa dizer que, quando o signo estiver estabelecido num grupo linguístico, não é possível que o indivíduo possa fazer qualquer coisa quanto a ele. Essa forma de pensar o arbitrário do signo está atrelada a uma maneira de conceber a linguagem em relação à coisa, pois ela vai contra a correspondência biunívoca entre esta última e a palavra. 
Em suma, o signo não deve ser o ponto de partida para se pensar a linguagem, uma vez que o significante não está restrito a função de representar o significado, não estando, portanto, restrito à lei de representação que não passa de uma ilusão, aquela em que "o significante atende à função de representar o significado, ou, melhor dizendo: de que o significante tem que responder por sua existência a título de uma significação qualquer" (Lacan, 1957, p. 500).

No trabalho $A$ instância da letra no inconsciente ou a razão desde Freud (Lacan, 1957), encontramos uma oposição ao esquema algoritmo saussuriano, uma espécie de duplicação paródica. Trata-se de um desenho que contém duas portas de banheiro, uma ao lado da outra. Sobre a primeira, encontra-se anotada a palavra homens e, sobre a segunda, mulheres. Vemos que os significantes (homens e mulheres) não se remetem, como a proposição de Saussure (1970), diretamente aos significados, em outras palavras, a seus conceitos.

Lacan (1957) traz à tona o referido exemplo não apenas para abalar o debate nominalista, como também para "mostrar como o significante de fato entra no significado, ou seja, de uma forma que, embora não seja imaterial, coloca a questão de seu lugar na realidade" (p. 503).

Nessa direção, vemos que a é lei da segregação ou seu imperativo sexual que determina uma separação material inscrita pelo significante como lugares distintos. O significante se inscreve como a própria lei, pois é a própria possibilidade da localização. Diz respeito à materialidade singular. $\mathrm{O}$ significante não se divide em lugares; pelo contrário, ele é quem divide os lugares, permitindo assim que a matéria exista por causa da divisão e não o inverso, ou seja, que haja divisão em consequência da matéria (Nancy, \& Lacoue-Labarthe, 1991).

Nesse sentido, Lacan (1957) retomou a situação do míope que se vê forçado a se aproximar das plaquinhas esmaltadas. A justificativa para essa referência se deve ao fato de que o míope não decifra o significado do significante inscrito, o que ele decifra é a diferença dos lugares. Entretanto, não se trata apenas disso, uma vez que esse espaçamento simboliza a diferença que a lei articula:

Se vê que, sem estender muito o alcance do significante implicado na experiência, ou seja, apenas duplicando a espécie nominal, pela simples justaposição de dois termos cujo sentido complementar parece ter que ser consolidado por ela, produz-se de duas portas gêmeas que simbolizam, com o reservado oferecido ao homem ocidental para satisfazer suas necessidades naturais fora da casa, o imperativo que ele parece compartilhar com a grande maioria das comunidades primitivas, e que submete sua vida pública às leis da segregação urinária (Lacan, 1957, p. 503).

Observamos o que o significante vai representar para Lacan, pois não se trata mais de uma mera face do signo que se articula em relação ao significado e 
de onde a sua existência é garantida. Mais do que isso, representa aquilo por meio do qual a lei como diferença se torna possível. Isso aponta, então, para o buraco estrutural em que a lei é marcada. Todas essas distinções implicam em uma só coisa: a visão lacaniana de que o significante apresenta uma supremacia sobre o significado. Tal fato fica evidente na análise do caso de Schreber, no qual Lacan (1955-1956) chegou à conclusão de que "no delírio, tudo se passa como se houvesse uma invasão progressiva do significante" (p. 247).

Após essa breve introdução ao significante e ao signo linguístico, podemos finalmente questionar: qual a relação entre o significante e a letra? Haveria uma distinção entre ambos?

Essas são umas das questões que só abordaremos ao longo deste texto, posto que primeiramente é preciso discutirmos a conhecida proposição de Lacan (1957), na qual a letra é apresentada como o suporte material do significante.

\section{A LETRA COMO SUPORTE MATERIAL DO SIGNIFICANTE}

O escrito lacaniano $A$ instância da letra no inconsciente ou a razão desde Freud (Lacan, 1957) é resultado de uma exposição realizada em 1957, na cidade de Sorbonne, para um grupo de Filosofia da Federação dos Estudantes de Letras. Nesse panorama, é interessante ressaltar que Lacan (1957) já não se dirigia apenas aos técnicos da análise. Sua fala agora estava voltada a um grupo de estudantes universitários marcados por uma "generalidade necessária" (Lacan, 1957, p. 497). Ele encontrou nesses estudantes uma acomodação propícia para sua exposição, sobretudo por causa da qualificação que os membros do grupo tinham em comum, a literária. Uma qualificação que lhe era, assim como para Freud, imprescindível na formação de analistas.

O termo "instância" presente no título, de acordo com Nancy e LacoueLabarthe (1991), foi primeiramente usado no sentido de uma insistente solicitação de argumento, ou de processo. Depois, fixou-se na língua clássica no sentido de autoridade judiciária. No francês moderno, o termo instânce é usado como autoridade tendo o poder de decisão. Em resumo, a instância é utilizada no título para designar a autoridade da letra, sua posição dominante: "O lugar de destaque que ela ocupa, de onde tem poder de decisão e exerce autoridade, de onde, em outras palavras, rege e legisla" (Nancy \& Lacoue-Labarthe, 1991, p. 32). Todavia esses mesmos autores não descartam a possibilidade de o termo ser usado também no sentido de insistência da letra. Já a segunda parte do título, ou a razão desde Freud, enfatiza que, após a ruptura operada por Freud na história 
do pensamento, a razão passa a ter outro sentido no inconsciente, o da instância da letra.

Ainda nesse texto, Lacan (1957) afirma que a letra deve ser tomada ao pé da letra e designada como "suporte material que o discurso concreto toma emprestado da linguagem” (p. 498). Nessa perspectiva, Lacoue-Labarthe e Nancy (1991) apresentam uma tentativa de definir o conceito de letra. Para tanto, adotam como ponto de partida a proposta de que "a letra designa a estrutura da linguagem na medida em que o sujeito nela está implicado" (Nancy \& Lacoue-Labarthe, 1991, p. 35). Tal implicação deve-se à relação do sujeito com a letra, no sentido de que este também deve ser tomado ao pé da letra. Uma literalização do sujeito, já que, conforme afirma Lacan (1957), "a linguagem, com sua estrutura, preexiste à entrada de cada sujeito num momento de seu desenvolvimento mental” (p. 498). Tratar-se-á, pois, de ver o sujeito como semelhante a um servo da linguagem, sobretudo do discurso, cujo lugar "já está inscrito em seu nascimento, nem que seja sob a forma de seu nome próprio” (Lacan, 1957, p. 498).

Dito isso, Lacan (1957) coloca em destaque dois conceitos: "discurso concreto" e "suporte material". O primeiro, para Lacoue-Labarthe e Nancy (1991), vincula-se ao elemento comum resultante da relação simultânea entre a linguagem como estrutura e a fala, adotada no sentido saussuriano de execução individual da língua. No tocante à noção de suporte material, os comentadores observam que, no escrito O seminário sobre "A carta roubada", Lacan (1956) destaca que, na novela de Poe, a carta não era encontrada justamente por estar localizada em um lugar evidente. Ele relacionou esse fato com a materialidade do significante.

Certamente, uma materialidade singular, já que não é possível determinar um lugar em que carta se encontra, ou não se encontra. Por outro lado, simultaneamente: "Ela estará e não estará onde estiver, aonde quer que vá" (Lacan 1956, p. 27). Trata-se, pois, da natureza do significante como sendo símbolo de uma ausência. Dessa forma, Lacan (1956) sustenta que, mesmo que a carta venha a ser picotada, ainda assim ela continuará sendo o que é: uma carta/letra.

No escrito Função e campo da fala e da linguagem em psicanálise, Lacan (1953/1998) abordou a linguagem como não sendo imaterial, sendo concebida mais especificamente pela relação desta com o corpo. É justamente nessa relação que é possível encontrar certas formas de somatização, a exemplo dos casos de histeria. Dessa maneira, quando a letra é associada ao suporte material, significa 
que é possível inferir que o sujeito, durante o ato de elocução, que se constitui pela relação com outrem, toma emprestado o material fornecido pela linguagem.

A materialidade da letra constitui em si uma dupla recusa no que se refere à origem desta, porque, por um lado, não se trata da idealidade do sentido e, por outro, não se refere a uma materialidade somática. Isso leva à consequência de outra recusa: a de se pensar o inconsciente como sediado pelos instintos e que tem uma materialidade substancial (Nancy, \& Lacoue-Labarthe, 1991). Considerando essa breve introdução, caminhamos agora à discussão concernente à distinção entre o significante e a letra.

\subsubsection{A LETRA LIXO}

Anos mais tarde, Lacan (1971a/2009) enfatiza a diferença entre a letra e o significante. Para ele, isso não se trata de uma nova perspectiva sobre o assunto, já que essa é sua postura ao escrever sobre a instância da letra no inconsciente, em vez da instância do significante no inconsciente. Assim, uma reflexão sobre o Seminário, livro 18: de um discurso que não fosse semblante (Lacan, 1971b/2009) se faz necessária. Nesse seminário, encontramos uma interessante releitura de Lacan quanto a seu texto de 1966, sobre o conto "A Carta Roubada".

Sabemos que, nesse trabalho, Lacan (1956) discutiu a questão da ordem simbólica e da constituição do sujeito por meio da obra de Edgar Allan Poe. Ele utilizou, de forma brilhante, os personagens e a trama para ilustrar a "determinação fundamental que o sujeito recebe do percurso de um significante" (Lacan, 1956, p. 14). Ele destaca ali duas cenas da história. A primeira foi denominada por ele de cena primitiva, não sem intenção, pois a segunda cena se revela uma repetição da anterior, uma situação que serve de analogia para o automatismo de repetição (Wiederholungzwang) proposto por Freud. Daí Lacan extrai seu princípio da insistência da cadeia de significante. A cena primitiva ocorre nos aposentos reais. A rainha, a primeira personagem ilustre que se faz presente, recebe uma carta no mínimo comprometedora, tendo em vista que, quando o rei adentra o recinto, ela se aproveita da distração do cônjuge e deixa a carta sobre a mesa, com a face para baixo, expondo assim apenas o sobrescrito.

Essa manobra foge aos olhos de todos, com exceção dos olhos atentos do ministro D. que, tendo percebido o desembaraço da rainha, inicia imediatamente uma manobra, retirando do bolso uma carta semelhante. Após encenar sua leitura, o ministro a deixa sobre a mesa para, em seguida, apoderar-se da carta da rainha. 
O gabinete do ministro é o local onde se passa a segunda cena. Após 18 meses de procuras meticulosas por parte da polícia, na mansão do ministro, nada foi encontrado. Para a resolução desse enigma, foi necessária a atuação direta do chefe de polícia, Dupin. Este marcou uma audiência com o ministro em seu gabinete. Com os olhos escondidos pelas lentes verdes dos óculos, ele vasculha o recinto até finalmente perceber sobre o painel da lareira, dentro de um simples porta-cartas de cartolina, a carta da rainha. Dupin, no dia seguinte, sob o pretexto de recuperar a sua tabaqueira, retorna ao gabinete, munido de um simulacro da carta, e assim, de semelhante forma à do ministro, substitui as cartas (Lacan, 1956).

Podemos observar que, na cena primitiva, a rainha tem consciência de que o ministro está com a carta, enquanto ao ministro não escapa o fato de que a rainha foi testemunha de seu ato. Por outro lado, na segunda cena, o ministro não tem consciência de que a carta foi levada. Em contrapartida, a rainha sabe muito bem que a carta não se encontra mais nas mãos do ministro. Também é importante ressaltar que, tanto a carta deixada pelo ministro sobre a mesa do rei como o simulacro deixado pelo chefe de polícia no gabinete do ministro, ambos apresentam um valor significante que não deve ser desprezado por qualquer analista, ao passo que a carta roubada ocupa o lugar do puro significante e, como tal, é símbolo de uma ausência, uma unidade de ser único: "Ela estará e não estará onde estiver, aonde quer que vá” (Lacan, 1956, p. 27). O deslocamento que os personagens sofrem de uma cena à outra se dá em razão do lugar ocupado por aquele puro significante. Do mesmo modo, na análise de Freud sobre a dívida do Homem dos Ratos, podemos observar, de acordo com Lacan, que essa dívida é um significante que tem um percurso complexo.

É no complexo intersubjetivo, observado no conto da carta roubada, que Lacan faz compreender o automatismo de repetição proposto por Freud e ilustra a determinação que o sujeito sofre em seus atos e em seu destino, constatada no caso do Homem dos Ratos: "Mas a carta/letra, tal como o inconsciente do neurótico, não o esquece. Esquece-o tão pouco que o transforma cada vez mais, à surpresa, e agora, a exemplo dela, ele irá cedê-la a uma surpresa semelhante" (Lacan, 1956, p. 38).

Como é possível notar, em O Seminário sobre "A carta roubada" (Lacan, 1956), a separação entre significante e letra ainda não é clara. Segundo Mandil (2003), nesse texto, as funções da lettre são determinadas pela dimensão do significante, sendo o conto de Poe, para Lacan (1956), um meio de estender suas teses sobre o significante. 
$\mathrm{Na}$ releitura que Lacan (1971b) promove, em O Seminário 18, acerca do escrito O Seminário sobre "A carta roubada" (Lacan, 1956), ele deixa claro que as articulações apresentadas por ele já estavam presentes naquele texto, bastando a quem se interesse apenas recorrer ao escrito. Dessa forma, ele inicia a exposição destacando que a tradução que melhor se enquadraria no título (The Purloined Letter) seria "a carta retida" (Lacan, 1971b, p. 92), em vez de "roubada", pois esta chega ao destino. Não se trata de qualquer destino, porque, para Lacan, a carta chega àqueles, a exemplo dos policiais, que nada podem compreender sobre ela. Justamente por não compreenderem o aspecto material da carta, a seu substrato, que os policiais falham em localizá-la no gabinete do ministro, mesmo tendo a certeza de que ali estava: "A carta, evidentemente, está fora do alcance da explicação do espaço, já que é disso que se trata” (Lacan, 1971b, p. 92).

O destino da carta vai se concretizar ao chegar àquele que Lacan (1971) denominou de sujeito. O sujeito vai se distinguir por uma "imbecilidade especialíssima” (Lacan, 1971b, p. 96), função que, no conto, é exercida pelo personagem do Rei, que não compreende nada e, mesmo que viesse a ter a carta em suas mãos, ainda assim, a única coisa que saberia é que ela tem um sentido.

Segundo Lacan (1971b), provavelmente só a Rainha sabe o que a carta quer dizer. Mas não é por causa disso que ela veio a ser localizada por Dupin, muito menos por causa da descrição que a Rainha apresenta aos policiais. Pelo contrário, segundo Mandil (2003), Lacan explica que é somente pela capacidade de perceber a dupla essência da carta que o chefe de polícia pode identificála no escritório do ministro, visto que este último, por sua vez, modificou o aspecto exterior da carta de tal forma que a descrição fornecida pela Rainha apenas contribui para o fracasso dos policiais.

Assim, por reconhecer que a carta não se encontra somente ao lado da mensagem, mas também tem um aspecto material que lhe permite ser manipulada ou até modificada, é que Dupin pode encontrá-la e substituí-la por um simulacro. Essa outra dimensão da carta, em que ela pode ser tomada como um objeto, e quem sabe amassada, riscada ou até picotada, remete-nos ao momento do ensino de Lacan em que este se refere à expressão joyciana: $a$ letter, a litter. Trata-se, na verdade, do artigo com o título de Lituraterre (Lacan, 1971a). Neste último, Lacan comenta que a palavra lituraterra foi inventada por ele. Como ele deixa claro, essa palavra não tem qualquer ligação etimológica com Littera, a letra, o que não o impede de fazê-la. Lacan, com base nos termos lino, litura e liturarius, vai propor a ligação entre litera (a letra) e litura. Segundo Mandil (2003), litura tem como origem a raiz latina lino e tem o sentido de cobertura ou, então, rasura. Com base em litura, forma-se a palavra liturarius, 
que tem o sentido de escrito com rasuras. Por meio dessa palavra, Lacan veio a conceber seu neologismo lituraterre.

O ponto de partida de Lacan para a criação desse neologismo vai ser a literatura de James Joyce, cuja expressão a letter, a litter foi abordada com base em uma tradução realizada por ele mesmo, como a passagem da carta/letra (a letter) para um lixo (a litter). Trata-se do saber fazer de James Joyce, com sua arte, como exemplo daquilo que melhor se pode almejar de uma psicanálise em seu fim, ou seja, o deslizamento de a letter para a litter. O que também pode ser pensado em relação à mudança que o ensino de Lacan sofreu em favor de uma promoção do escrito, ele afirma: "Aqui, porém, meu ensino situa-se numa mudança de configuração que, atualmente, a pretexto da atualidade, anuncia com um lema de promoção do escrito" (Lacan, 1971b, p. 107).

Conforme Mandil (2003), o artigo Lituraterre, contemporâneo ao Seminário 18 , representa o momento em que a lettre vai ocupar um lugar central no ensino de Lacan, embora ainda não exista uma distinção clara entre significante e letra. Nesse artigo, a letter é pensada em uma contraposição ao significante, tendo como base uma associação gradativa com a noção de gozo.

Quanto a esse ponto, não é de se surpreender que Lacan (1971b) retorne mais uma vez ao conto de Poe. Seu intuito foi relembrar que aquela carta, apesar de seus constantes desvios, sempre chega a seu destino, mas não sem antes promover um efeito ilusório, o qual Lacan denomina efeito de feminizaçã $o^{2}$ sofrido por aqueles que a possuíam. Todavia, a ênfase de Lacan centra-se no aspecto de que a jornada que a carta/letra percorre ocorre sem qualquer referência ao seu conteúdo. Com isso, Lacan realiza, claramente, uma separação entre a carta/letra e o significante, no sentido de que a escrita, a materialidade desconecta de qualquer sentido, é o que seria realmente a responsável pelas "peripécias" (Lacan, 1971b, p. 107) da carta.

O sentido/saber, se é que podemos colocar dessa maneira, é o que Lacan vai questionar neste momento, não somente por causa do fato de que a carta foi localizada em detrimento do conteúdo, mas também devido à relação da psicanálise com o furo, ou seja, com o saber em xeque que permite que esta revele aquilo que tem de melhor. Assim, Lacan (1971b) propôs que o fato de a psicanálise poder fazer furo é que ela pode vir a representar uma renovação na crítica literária: "O que significa que a crítica literária viria efetivamente a se renovar pelo fato de a psicanálise estar aí para os textos se medirem por ela,

\footnotetext{
${ }^{2}$ De acordo com Eric Laurent, citado por Oliveira (2008, p. 23), o efeito de feminização que a carta/letra promove naquele que a esconde está relacionado à ideia de enigma, como lugar de gozo que faz furo no sentido.
} 
justamente por ficar o enigma do seu lado, por ela se calar" (Lacan, 1971b, p. 108).

Diante dessa nova separação entre significante-mestre e letra, ou seja, entre o aspecto de sentido/saber da lettre e o aspecto de gozo que traz uma materialidade desprovida de sentido, Lacan (1971b) levantou um questionamento: "Quanto a mim, eu lhes digo, será que a letra não é o literal a ser fundado no litoral?” (p. 109). Com esse ponto, ele introduz na letra uma relação de litoral que, por ser diferente de uma fronteira, constitui-se demarcando uma linha divisória entre heterogêneos.

É entre mar e terra, entre gozo e saber, que se apresentam os dois elementos heterogêneos com os quais Lacan (1971b) vem a exemplificar o litoral que a letra constitui, já que a passagem de um para o outro não é possível sem considerarmos a borda do furo que a letra desenha. Aqui recorremos ao artigo Lituraterra (Lacan, 1971a), pois julgamos que esta passagem se revela mais explícita quanto ao assunto:

A borda do furo no saber, não é isso que ela desenha? E como é que a psicanálise, se justamente o que a letra diz por sua boca "ao pé da letra" não lhe conveio desconhecer, como poderia a psicanálise negar que ele existe, esse furo, posto que, para preenchê-lo, ela recorre a invocar nele o gozo? (Lacan, 1971a, p. 18).

No entanto, não podemos deixar de citar $O$ seminário 18 , a considerar os esclarecimentos que este nos apresenta sobre a letra como litoral entre gozo e saber:

O curioso é constatar como a psicanálise se obriga, como que de modo próprio, a reconhecer o sentido daquilo que a letra, no entanto, diz ao pé da letra, seria o caso de dizer, quando todas as suas interpretações se resumem ao gozo. Entre o gozo e saber, a letra constituiria o litoral (Lacan, 1971b, pp. 109-110, grifo do autor).

Ainda se referindo à ideia de fronteira e litoral, Lacan (1971b) recorre a uma história de sua biografia, que se passou quando estava retornando à França, após uma segunda visita ao Japão. Ele explica que a observação que ele fez não ocorreu durante a primeira viagem. Foi por causa das limitações de rotas impostas pelos soviéticos que o avião teve de percorrer uma nova rota pelo círculo ártico, passando pela planície da Sibéria.

Lacan (1971b) recordou daquela viagem a visão do escoamento das águas sobre a planície siberiana, esse traço de escoamento que, não sem propósito, vai ser descrito entre as nuvens. Ele associou o escoamento com o buquê do esquema óptico apresentado por ele em ensinos anteriores, mas que ali remete-se ao sentido de traço unário, "o significante, não de uma presença, mas de uma ausência 
apagada” (Lacan, 1961-1962), isto é, uma marca que destaca a diferença por sempre passar por um apagamento. Assim, quando Lacan afirma que o sujeito é designado pelo apagamento do traço unário, ele está se referindo à diferença de si mesmo introduzida pelo traço, que serve de suporte à identificação do sujeito.

Nesse escoamento, o que se deve distinguir é "a rasura de traço algum que seja anterior” (Lacan, 1971b, p. 113), do mesmo modo que a presença das nuvens nos remete novamente à ideia de litoral que divide heterogêneos, visto que o escoamento se conjuga com sua fonte: as nuvens.

Dessa forma, Lacan (1971b) identifica as nuvens como representando o simbólico: "pois é justamente nas nuvens que Aristófanes me conclama a descobrir o que acontece com significante, ou seja, o semblante por excelência" (p. 114). Por outro lado, a precipitação da chuva constitui um rompimento desse semblante, o que resulta em riachos que cortam a terra. Nesse ponto, vemos o sentido de litoral, visto que, para Lacan, a letra é uma precipitação do significante. Por isso, a letra produz a ruptura do simbólico, fazendo com que a matéria, que estava em suspensão, se precipite, ao mesmo tempo em que o rompimento terá um efeito no real. Nesse sentido, o gozo, como uma torrente de água, vai erodir e aprofundar as depressóes da terra.

A letra como precipitação do significante implica uma primazia do significante em relação à letra. Na verdade, na passagem de Lituraterra enfatizada por Lacan (1971b), não se deve confundir a letra com o significante. Da mesma maneira, não se deve atribuir à letra uma primazia em relação ao significante: "O que escrevi com a ajuda de letras sobre as formaçôes do inconsciente não autoriza a fazer da letra um significante, e a lhe atribuir, ainda por cima, uma primazia em relação ao significante" (Lacan, 1971b, p. 110).

A erosão, ou, como Lacan se refere em $O$ seminário 18 , o "ravinamento das águas" (Lacan, 1971b, p. 114), serve-lhe para definir a escrita, não somente como estando do lado do real, mas como uma erosão do significado. Nas palavras de Lacan: "Isto é para lhes definir por que se pode dizer que a escrita é, no real, o ravinamento do significado, ou seja, o que choveu do semblante como aquilo que constitui o significante" (Lacan, 1971b, p. 114). Lacan vai mais além, ao abordar a escrita como aquilo que se diferencia do semblante, ou seja, da ordem simbólica, pois seu vazio escavado consiste em um receptáculo que sempre está pronto a receber o gozo, o qual se desprende de toda ruptura do semblante, como afirma: "que nada é mais distinto do vazio cavado pela escrita do que o semblante na medida em que, para começar, ela é o primeiro de meus godês a estar sempre pronto a dar acolhida ao gozo, ou, pelo menos, a invocá-lo com seu artifício" (Lacan, 1971b, p. 118). 
Trata-se da dinâmica entre o gozo e a ruptura do simbólico que, segundo Mandil (2003), pode ser recordada em $O$ seminário sobre "A carta roubada" (Lacan, 1956), já que a carta do conto só foi encontrada por causa da habilidade de Dupin de ver além da descrição, em outras palavras, além do semblante a ela imposta. A carta havia sido alvo do gozo do ministro e, assim, o semblante sofrera rupturas, isto é, um falsear de sua forma primeira de objeto.

O que também pretendemos enfatizar está relacionado ao efeito que a letra exerce sobre aqueles que a possuem, porque como Lacan observa no decorrer do conto, o ministro sofre alteraçóes, "tais como as variaçóes de cor de um peixe a deslizar" (Lacan, 1971b, p. 96). A causa para tanto é que a letra tem um efeito de feminização.

Esse efeito feminilizante da carta/letra nos conduz a $O$ seminário 20, no qual Lacan (1972-1973/2008) dedica-se ao tema do gozo, especialmente ao gozo feminino. O gozo feminino apresenta uma perspectiva de que a escrita situa-se como "suplência desse não todo sobre o qual repousa o gozo da mulher" (Lacan, 1972-1973, p. 41). Trata-se da impossibilidade da relação sexual que impede o homem de gozar do corpo da mulher. Assim, quando o homem pensa que aborda uma mulher, na verdade, o que ele aborda é aquilo que Lacan denomina de objeto $a$, objeto causa de desejo. A mulher, por sua vez, não está impedida de gozar falicamente, pelo contrário, ela está livre para isso. Mas, o que acontece com todo ser falante, que "se alinha sob a bandeira das mulheres" (Lacan, 19721973, p. 78), é que este vai se fundar por ser não todo. Com base nessa essência da mulher é que Lacan se refere a um gozo suplementar quando se trata do gozo à função fálica.

Lacan (1972-1973) observa que o direito serve de exemplo para a ideia de gozo que propõe, pois a noção de usufruto lhe permite trazer à tona a diferença entre o útil e o gozo. Pois, por um lado, o termo jurídico, como usufruto de uma herança, caracteriza a essência do direito de tentar dar uma utilidade a tudo àquilo que pertence à esfera do gozo, ou seja, como Lacan coloca: "repartir, distribuir, retribuir" (Lacan, 1972-1973, p. 11). Por outro lado, ele traz uma noção de gozo que se opõe a essa utilidade. Assim, o gozo sexual vai ser pensado por Lacan como um resto inútil. Essa concepção justifica a evocação de Lacan da expressão joyciana a letter, a litter, tendo em vista a articulação entre o elemento simbólico, a letter, e o elemento de gozo residual, a litter, lixo (Mandil, 2003). 


\subsubsection{A ESCRITA “A NÃO SE LER”}

Lacan (1971a), ainda com base nessa separação entre a escrita e o significante, afirma: "A escrita não é de modo algum do mesmo registro, da mesma cepa, se vocês me permitem esta expressão, que o significante" (Lacan, 1972-1973, p. 35). Nesse texto, ele também apresenta uma distinção entre o escrito e a leitura, ou pelo menos ao que normalmente se pode pensar sobre o que seria uma leitura. Isso fica claro com o exemplo da publicação de seus Escritos, em que confidencia que os tinha como sendo para não serem lidos. Desse modo, por mais que estejamos inclinados a conceber a leitura de uma letra como sendo semelhante a uma leitura de uma carta, não se trata do mesmo.

Uma boa leitura da letra se encontra em um para além, tal como se faz no discurso analítico em que se lê para além do que o sujeito foi incitado a dizer. Aqui se trata de uma postura clínica que Lacan (1972-1973) nos instiga a adotar diante da fala do sujeito, no sentido de promover uma separação entre significante e significado, dando ênfase ao primeiro. Isso vai ao encontro da interpretação do inconsciente, visto que Freud (1900/1996), em Interpretação dos sonhos, sugere que os sonhos devam ser lidos de semelhante forma a uma escrita hieroglífica, ou chinesa, em outras palavras, uma escrita em que o desenho se encontra incorporado em sua expressão. Para Lacan (1972-1973), essas imagens de sonhos devem ser tomadas como letras e lidas como tal.

Mas a que este para além se refere na boa leitura? Lacan (1972-1973) trouxe uma questão sobre o efeito da escrita em um discurso, mais especificamente o que se produz por este efeito. Ele afirma que o que pode nos introduzir na dimensão da escrita é percebemos o fato de que o que se ouve é o significante e não o significado, apresentando uma distinção no que diz respeito à leitura, porque o que se lê não é o significante. Somente a partir do que se ouve do significante é que algo, enfim, poderá ser lido.

A leitura não ocorre em razão de um significante que não se lê, mas naquilo que se ouve deste. Sobre o significado, Lacan (1972-1973) comenta que ele é o efeito do significante, efeito que não tem relação com o que se ouve, mas sim com a leitura que se realiza a partir do que se ouve do significante. Dito isso, outras questôes podem se fazer presentes: a que leitura Lacan está se referindo? Existe mais de uma forma de leitura de um escrito? Encontramos, na última parte da aula sobre a função de escrito, uma possível resposta, no momento em que Lacan (1972-1973) nos instiga a ler a obra Finnegans wake, de Joyce (2012). Ele comenta que a referida obra de Joyce é uma escrita que "se lê mal, ou que se lê de través, ou que não se lê" (Lacan, 1972-1973, p. 42). 
Ao referenciar o escrito de Joyce, Lacan traz à tona um exemplo de obra na qual se joga com a escrita de tal forma que a linguagem acaba por se aperfeiçoar. Um trabalho com o significante que se aproxima muito do discurso do analista, no que concerne à leitura de um lapso. Esta aproximação se deve ao modo como Joyce (2012) em Finnegans wake toma os significantes, como aqueles capazes de se "se embutirem, se comporem, se engavetarem" (Lacan, 1972-1973/2008, p. 42), resultando, assim, em algo na esfera do significado que se aproxima ao enigma.

Como é de se imaginar, a leitura de uma obra em que "o significante vem a rechear o significado" (Lacan, 1972-1973, p. 42) se revela uma tarefa, segundo Lacan, impossível. Dito de outro modo, tudo aquilo que poderia representar uma leitura de sentido, ou de compreensão, acaba caindo por terra devido à multiplicidade de leituras que o significante dá margem. É justamente nesse ponto que Lacan faz uma aproximação com a leitura do lapso, pois "o de que se trata no discurso analítico é sempre isto - ao que se anuncia de significante, vocês dão sempre uma leitura outra que não o que ela significa" (Lacan, 19721973, p. 43).

Assim, chegamos a uma resposta ao questionamento sobre a inexistência de uma única forma de ler um escrito. Com base nisso, Lacan questiona a suposta continuidade entre a leitura e o escrito. Além disso, fundamenta a hipótese que pode ser encontrada de modo direto no Posfácio ao Seminário 11 (Lacan, 1973/2003), de que o escrito não é para ser lido. Algo que não está restrito aos achados de Lacan, como ele mesmo pontua, porque, muito antes dele, foi Joyce quem introduziu o escrito como "não a ler".

Lacan joga com as palavras "introduz" e "intraduz", certamente uma homenagem ao estilo joyciano, mas que serve como referente à impossibilidade de leitura, porque toda leitura abriga uma tradução. Segundo Mandil (2003), o prefixo negativo in de "intraduz" também pode ser tomado no sentido de elemento locativo, trazendo, assim, uma ideia de "dentro, em", o que, para o comentador, diz respeito a uma autotradução que o texto efetua.

Esta ideia de autotradução do texto nos é cara para o entendimento da ilegibilidade da obra Finnegans wake (Joyce, 2012), visto que se trata de um texto onde a cada momento uma autoleitura se apresenta, porém sem que se acene a possibilidade de uma interpretação final. Assim, como Mandil (2003) comenta, é como se interpretação passasse a se fundamentar em um ajuste contínuo.

A referência que Lacan traz da leitura do grande livro do mundo, presente tanto em O seminário 20 (Lacan, 1972-1973) como no Posfácio ao Seminário 
11 (Lacan, 1973), serve-nos de ilustração para pensar a escrita como "não a ler". De semelhante maneira, veremos uma autoleitura do inconsciente representada pelo lapso. Lacan (1938/2003) interroga: "Será que a abelha lê que ela serve à reprodução das plantas fanerógamas? Será que o pássaro lê o augúrio da fortuna, como diziam antigamente, quer dizer, da tempestade?" (p. 43). O discurso analítico vai ser referenciado nessa analogia, uma vez que a leitura que se faz em torno do "escrito" do voo das abelhas e dos pássaros aponta, respectivamente, para o sentido de polinização e presságio de tempestades, não passando de associações de significantes isolados com significados, o que sempre representa outra leitura daquilo que realmente significa.

Ante essa ideia de outra leitura, Lacan salienta abordar, em sua analogia, a possibilidade de que a andorinha leia a tempestade. Essa suposição de leitura do passarinho serve de gancho para aquilo que interessa ao discurso analítico, por conseguinte: "No discurso analítico de vocês, o sujeito do inconsciente, vocês supõem que ele sabe ler. E não é outra coisa, essa história do inconsciente, de vocês" (Lacan, 1972-1973, p. 43). Nota-se que Lacan traz a questão da autoleitura para o inconsciente, a exemplo, como já abordamos, do lapso, posto que, no lapso, é como se o inconsciente estivesse interpretando, ou seja, promovendo uma autoleitura da intenção de significação (Mandil, 2003). Porém Lacan deixa uma ressalva, porque, mesmo que haja a suposição de que o sujeito do inconsciente saiba, ou, então, aprenda a ler, apesar disso, aquilo que o analista ensina como forma de ler, não mantém relação alguma com aquilo que "vocês possam escrever a respeito" (Lacan, 1972-1973, p. 43).

Ao visar a hipótese de separação da escrita e da leitura, Lacan (1973) realiza, no Posfácio ao Seminário 11, uma crítica ao processo de alfabetização, a qual ele se refere ao neologismo "alfabestificando-se" (Lacan, 1973, p. 504). Para o psicanalista, o processo de aprendizagem de leitura da escrita fonética, em que a criança aprende a associar o som da letra $G$ através de desenhos de girafas e gorilas, não tem relação alguma com a dimensão do escrito.

Ainda no posfácio, Lacan (1973) recorre ao tão conhecido chiste relatado por Freud (1905/1996) em sua obra, Os chistes e sua relação com o inconsciente, em que dois judeus se encontram na estação da Galícia. Então o primeiro pergunta para qual destino o segundo se dirigia. Este responde que estava indo para a Cracóvia. De fato, o primeiro não se contenta e o acusa de mentiroso, justificando que a intenção deste era fazê-lo acreditar que estava indo para Lemberg. $\mathrm{Na}$ verdade, estava realmente indo para a Cracóvia. É na dimensão da fala do primeiro judeu para o segundo que encontramos uma demanda de interpretação e uma pergunta sobre a verdadeira intenção, ou seja, "Por que você mente para mim ao me dizer a verdade?" (Lacan, 1973, p. 504). Lacan (1973) deixou claro que 
não é na suposta leitura do guia de horário da estrada de ferro que o impasse será resolvido, principalmente porque esta não seria a verdadeira função de um escrito nessa história. Para Lacan (1973) a função do escrito, neste caso do chiste, seria representada pelo caminho da estrada de ferro, o que remete a mais de uma possibilidade de destino: Lemberg ou Cracóvia. É com base nisso que Mandil (2003) vai retomar a obra Finnegans wake (Joyce, 2012): cada palavra ou frase vai dar margem a uma multiplicidade de interpretaçôes, mantendo assim em suspenso a demanda à interpretação.

A demanda à interpretação, como é possível perceber no questionamento feito pelo judeu ao outro, vai representar um aspecto fundamental, uma presença de mais de gozar, que, segundo Lacan, chega-se percorrendo os trilhos da estrada de ferro, o objeto $a$. Assim, ele nos indica, na função do escrito, a presença do objeto a. Além disso, de um gozo no escrito, cuja presença serve para fundamentar a multiplicidade de leituras. Por fim, pensamos que isso se constitui como um palco fértil à concepção da interpretação como distinta de um deciframento, tornando possível uma reflexão sobre o fim de análise. 


\section{REFERENCIAS}

Arrivé, A. (2001). Linguística e psicanálise: Freud, Saussure, Hjeimslev, Lacan e os outros. São Paulo: Editora da Universidade de São Paulo.

Freud, S. (1900/1996). A interpretação dos Sonhos. In J. Salomão (Trad.), Edição standard brasileira das obras psicológicas completas de Sigmund Freud. (Vol. 4, pp. 13-363). Rio de Janeiro: Imago, 1996. (Publicado originalmente em 1900).

Freud, S. (1905/1996) Os chistes e a sua relação com o inconsciente. In J. Salomão (Trad.), Edição standard brasileira das obras psicológicas completas de Sigmund Freud. (Vol. 8, pp. 17-233). Rio de Janeiro: Imago, 1996. (Publicado originalmente em 1905).

Joyce, J. (2012). Finnegans wake. Londres: Wordsworth.

Lacan, J. (1938/2003). Os complexos familiares na formação do indivíduo: ensaio de análise de uma função em psicologia In Outros escritos. (pp. 29-90). Rio de Janeiro: Jorge Zahar, 2003. (Publicado originalmente em 1938).

Lacan, J. (1953/1998). Função e campo da fala e da linguagem em psicanálise. In Escritos. (pp. 238-324). Rio de Janeiro: Jorge Zahar, 1998. (Publicado originalmente em 1953).

Lacan, J. (1955-1956/2008). O seminário: livro 3: as psicoses. Rio de Janeiro: Jorge Zahar, 2008. (Publicado originalmente em 1955-1956).

Lacan, J. (1956/1998). O seminário sobre "A carta roubada”. In J Lacan. Escritos. (pp. 13-66). Rio de Janeiro: Jorge Zahar, 1998. (Publicado originalmente em 1956).

Lacan, J. (1957/1998). A instância da letra no inconsciente ou a razão desde Freud. In. J. Lacan. Escritos. (pp. 496-533). Rio de Janeiro: Jorge Zahar, 1988. (Publicado originalmente em 1957).

Lacan, J. (1961-1962). O seminário: livro 9: a identificação. (Trabalho não publicado).

Lacan, J. (1971a/2003). Lituraterra In J. Lacan. Outros escritos. (pp. 15-25). Rio de Janeiro: Jorge Zahar, 2003. (Publicado originalmente em 1971). 
Lacan, J. (1971b/2009). O seminário: livro 18: de um discurso que não fosse semblante. Rio de Janeiro: Jorge Zahar, 2009. (Publicado originalmente em 1971).

Lacan, J. (1972-1973/2008). O seminário: livro 20: mais, ainda. Rio de Janeiro: Jorge Zahar, 2008. (Publicado originalmente em 1972-1973).

Lacan, J. (1973/2003). Posfácio ao Seminário 11. In J. Lacan. Outros escritos. (pp. 503-507) Rio de Janeiro: Jorge Zahar, 2003. (Publicado originalmente em 1973).

Mandil, R. (2003). Os efeitos da letra: Lacan leitor de Joyce. Rio de Janeiro: Contra Capa.

Nancy, J.-L., \& Lacoue-Labarthe, P. (1991). O título da letra: uma leitura de Lacan. São Paulo: Escuta.

Oliveira, E. S. (2008). Nicas, nonadas, tutameíces: o percurso da letra na obra de Guimarães Rosa. (Tese de Doutorado). Programa de Pós-graduação em Letras, Universidade Federal de Minas Gerais, Belo Horizonte.

Saussure, F. (1970). Curso de Linguistica Geral. São Paulo: Cultrix. 